\title{
Effects of statin therapy on outcomes of ischemic stroke: a real-world experience in Brazil
}

\author{
Efeitos da terapia com estatinas nos desfechos do acidente vascular cerebral isquêmico: \\ uma experiência de mundo real no Brasil
}

Bruno Kusznir VITTURI', Rubens José GAGLIARDI

\begin{abstract}
Background: Statin therapy has become one of the most important advances in stroke secondary prevention. Objective: To provide evidence from real-world data for evaluating detailed associations between secondary prevention of stroke and statin use in Brazil. Methods: We conducted a prospective cohort study including consecutive patients diagnosed with an ischemic stroke. Subjects were classified into non-statin, simvastatin $20 \mathrm{mg}$, simvastatin $40 \mathrm{mg}$, and high-potency statin groups. We also registered the onset of statin therapy, previous use of statins, the adherence to medication, and if there was discontinuation of the therapy. After two years, the functional outcome, stroke recurrence, major cardiovascular events, and mortality were assessed. Results: Among the 513 patients included in our cohort, there were 96 (18.7\%) patients without statins, 169 (32.9\%) with simvastatin 20 mg, 202 (39.3\%) with simvastatin 40 mg, and 46 (9.0\%) with highpotency statins. Patients without statins were at increased risk of stroke recurrence and worse functional outcomes. Concerning etiology, evidence of beneficial use of statins was observed in cases of large-artery atherosclerosis, small-vessel occlusion, and stroke of undetermined cause. Those who presented poor adherence to statins or discontinuation of the treatment had worse prognosis after stroke whereas the early onset of statins use was associated with better outcomes. Patients with simvastatin 40 mg and high-potency statins presented the best functional recovery throughout the follow-up. Conclusions: Statins play an important role in the treatment of ischemic stroke, preventing stroke recurrence and cardiovascular events, and improving functional performance.
\end{abstract}

Keywords: Statin; Ischemic stroke; Outcomes; Prevention.

\section{RESUMO}

Introdução: A terapia com estatinas tornou-se um dos avanços mais importantes na prevenção secundária do acidente vascular cerebral (AVC). Objetivo: Fornecer evidências de dados do mundo real para avaliar associações detalhadas entre a prevenção secundária do AVC e o uso de estatinas no Brasil. Métodos: Realizamos um estudo de coorte prospectivo, incluindo pacientes consecutivos com diagnóstico de AVC isquêmico. Os indivíduos foram classificados em grupos sem estatinas, sinvastatina 20 mg, sinvastatina 40 mg e estatina de alta potência. Também registramos o início da terapêutica com estatinas, o uso prévio de estatinas, a adesão à medicação e se houve descontinuação da terapia. Após dois anos, foram avaliados o resultado funcional, a recorrência do AVC, os principais eventos cardiovasculares e a mortalidade. Resultados: Entre os 513 pacientes incluídos em nossa coorte, havia 96 (18,7\%) pacientes sem estatinas, 169 (32,9\%) com sinvastatina 20 mg, 202 (39,3\%) com sinvastatina 40 mg e 46 (9,0\%) com estatinas de alta potência. Pacientes sem estatinas apresentaram maior risco de recorrência de AVC e piores resultados funcionais. Em relação à etiologia, foram observadas evidências do benefício das estatinas nos casos de aterosclerose de grandes artérias, oclusão de pequenos vasos e AVC de causa indeterminada. Aqueles com baixa adesão às estatinas ou que interromperam o uso tiveram pior prognóstico após o AVC, enquanto o início precoce do uso de estatinas foi associado a melhores resultados. Pacientes com sinvastatina $40 \mathrm{mg}$ e estatinas de alta potência apresentaram melhor recuperação funcional ao longo do período de acompanhamento. Conclusões: As estatinas desempenham um importante papel no tratamento do AVC isquêmico, prevenindo sua recorrência e eventos cardiovasculares e melhorando o desempenho funcional.

Palavras-chave: Estatinas; Acidente vascular cerebral isquêmico; Desfechos; Prevenção.

\footnotetext{
'Santa Casa de São Paulo, School of Medical Sciences, Department of Neurology, São Paulo SP, Brazil.

Bruno Kusznir VITTURI (D) https://orcid.org/0000-0002-2821-9042; Rubens José GAGLIARDI (D) https://orcid.org/0000-0002-3497-0174

Correspondence: Bruno Kusznir Vitturi; E-mail:z_azul@hotmail.com

Conflicts of interest: There is no conflict of interest to declare.

Received on December 02, 2019; Received in its final form on February 03, 2020; Accepted on February 17, 2020.
} 


\section{INTRODUCTION}

Stroke is the second leading cause of death and disability in Latin American countries and worldwide ${ }^{1}$. The absolute number of people with incident strokes has significantly increased by $81 \%$ from 1990 to 2017, the number of people who survived by $95 \%$, and the number of those who died from stroke by $40 \%^{2}$. Given these numbers, the importance of adopting effective secondary prevention strategies is paramount ${ }^{3}$. Statin therapy has become an essential advance in stroke prevention since the introduction of aspirin and blood pressure-lowering therapies ${ }^{4}$. Positive results from clinical trials have already evaluated the efficacy and safety of statins in stroke, leading to an increase in the use of statins for these patients 5 .

However, since then, no real-world study has ever been conducted in a stroke population. Besides, the vast majority of studies on statins and stroke have been performed in populations with notably different scenarios from developing countries ${ }^{6}$. In Brazil, for example, there is no previous research regarding the role of statins in the outcomes of stroke patients. Patients who receive treatment in the real world can differ in important ways from the patients enrolled in the clinical trials for that treatment. Randomized clinical trials are usually limited to the assessment of a single therapeutic intervention, and they have severe inclusion and exclusion criteria, which often distances the outcome of the neurologist's reality. Moreover, real-world studies can help us better understand how the treatment is used in everyday clinical practice?

Furthermore, many questions regarding the use of statins in stroke have not yet been answered by clinical trials. Providing appropriate management to patients with acute stroke depends on the underlying etiology of stroke. Nevertheless, no previous studies compared the effects of statins on different types of stroke, so current evidence only supports the use of statins to atherothrombotic stroke patients ${ }^{8}$. Also, it is still unknown whether prior use of statins influences neurological outcomes after a stroke. Similarly, the equivalence of statin types and doses is still uncertain, and the real consequences of discontinuing statin therapy lack clarity 9 .

To date, evidence from real-world data for evaluating detailed associations between secondary prevention of stroke and statin use is lacking. Therefore, we performed this study to address most of these issues.

\section{METHODS}

\section{Study design and cohort population}

We carried out a prospective cohort study composed of consecutive patients admitted to the Department of Neurology of a university-affiliated tertiary referral hospital, who were under regular clinical follow-up between January 2014 and August 2018. Patients aged 18 years or older with a first-ever ischemic stroke were considered eligible for the study. Stroke was defined according to the World Health Organization as a sudden focal neurologic deficit persisting longer than 24 hours and confirmed by brain CT or MRI.

We excluded patients who used other lipid-lowering drugs and those that were followed up for $<24$ months for any reason. Patients were followed up by telephone interviews and face-to-face assessments in the outpatient department for two years. Senior neurologists who were utterly blinded to the study conducted the interviews. All participants provided written informed consent before inclusion, and the research protocol was approved by our local ethics committee.

\section{Baseline measures and comorbidities}

Baseline characteristics of stroke patients were recorded on admission. When the patient was discharged, information about stroke subtype, treatment in hospital, complications, laboratory tests, and CT and/or MRI findings were recorded. The data collectors were not aware of the study. Stroke severity was measured using the NIH Stroke Scale (NIHSS) score on hospital admission.

Statins were individually prescribed without consideration of the low-density lipoprotein cholesterol level. Consecutive patients were distinguished into four groups according to the particularities of statin therapy. One group consisted of patients receiving simvastatin $20 \mathrm{mg}$ per day and another group receiving simvastatin $40 \mathrm{mg}$ per day. Patients receiving atorvastatin $40 \mathrm{mg}$ per day or rosuvastatin $10 \mathrm{mg}$ per day were regarded as receiving highintensity statin therapy. The high-potency statin group was defined by patients who have prescribed a dose and type of statin that was expected to reduce the initial lowdensity lipoprotein cholesterol level by more than $50 \%^{10}$. Patients who did not use statins were included in a separate group as well. Statin use onset was registered for each patient. Previous statin treatment referred to regular use of statins at least one month before the stroke. Treatment in the acute phase was defined as statins initiated within 72 hours after stroke onset, while late-onset treatment was defined as when it was initiated three days after stroke onset. Adherence to statin treatment was evaluated using the 8-item Morisky Medication Adherence Scale (MMAS-8) ${ }^{11}$. Total scores range from 0 to 8 , and patients were considered adherent only with scores higher than 6 .

\section{Main outcomes measures}

The individuals were followed until death or until two years after the stroke onset. If no clinical evaluation could be performed during this period, first, the patient was searched in the National Registry of Death to detect 
a possible death before being excluded from the analysis. The primary outcome was the post-stroke functional limitations that were assessed using the modified Rankin Scale (mRS) at 7 days, 30 days, 6 months, and 2 years after hospital admission for ischemic stroke. We defined an unfavorable outcome as mRS score $\geq 3$, and a favorable outcome as $\mathrm{mRS}$ score $\leq 2$. Each patient had the mRS calculated by two different doctors, one of whom was blind to the study. In case of discrepancy, the opinion of the head of the stroke outpatient clinic was consulted. Secondary outcomes included all-cause mortality, stroke recurrence (ischemic or hemorrhagic), and major cardiovascular events.

\section{Statistical analysis}

Categorical variables were analyzed using the chi-square test or Fisher's exact test, and differences in continuous variables were assessed using the Student's t-test (parametric test) or the Mann-Whitney test (non-parametric test). Odds ratios (ORs) were derived from a multivariable logistic regression with each outcome categorized by statin exposure. Confounding variables included age, sex, stroke severity, medications, smoking, and other comorbidities ${ }^{12}$. The limit for significance was set at 2 -tailed $\mathrm{p}=0.05$. All analyses were conducted using SPSS, version 23.0.

\section{RESULTS}

Five hundred forty-six patients were identified as having an ischemic stroke during the study period. Of this group, 33 were excluded because of exclusion criteria or loss of follow-up, leaving 513 patients for analysis (Figure 1). Of those analyzed, $417(81.3 \%)$ were exposed to a statin, and 96 $(18.7 \%)$ were not. There were 169 (32.9\%) with simvastatin $20 \mathrm{mg}, 202$ (39.3\%) with simvastatin $40 \mathrm{mg}$, and 46 (9.0\%) with high-potency statins. The mean age of the participants was 56.7 (SD 15.1) years, and 236 (46.4\%) were female. The demographics and clinical features of the cohort are presented in Table 1. There were no significant differences in sex, history of the previous stroke, NIHSS, atrial fibrillation, smoking, alcohol abuse, carotid stenosis, and anticoagulation therapy. Older patients, patients with cardiovascular factors (coronary heart disease, dyslipidemia, diabetes, hypertension), and those who

We registered 11 (2.1\%) deaths during follow-up, and 25 (4.9\%) patients had major cardiovascular events. There were four $(0.8 \%)$ cases of hemorrhagic stroke as well (two were without statins, one with simvastatin $40 \mathrm{mg}$, and other with a high-potency statin). Concerning recurrent stroke, 104 (20.3) patients had a recurrence during followup. A detailed description of the profile of the patient who had another stroke is represented in Figure 2. Patients with statins had a lower risk of major cardiovascular events
( $\mathrm{OR}=0.3 ; 0.1-0.7 ; \mathrm{p}=0.01)$. Regarding mortality, there was no difference according to statin use (OR=0.6; $0.1-2.3 ; \mathrm{p}=0.73$ ). The median mRS was 2, and 307 (59.8\%) had a favorable functional outcome.

Most enrolled patients were pre-stroke statin nonusers ( $\mathrm{n}=441 ; 86.0 \%)$. However, no benefit related to previous statin use was found (Table 2). Only 209 (40.7\%) of subjects begun statin treatment at stroke onset. Early-onset of statin use was associated with better neurofunctional outcomes and a lower chance of stroke recurrence $(\mathrm{p}<0.01)$. Among statin users, there were 54 (10.5\%) cases of statin withdrawal, and only $154(30.0 \%)$ patients presented satisfactory adherence to the treatment. Poor adherence and treatment discontinuation were also associated with a worse functional outcome and a higher chance of having another stroke $(\mathrm{p}<0.01)$.

Patients who received no statin treatment had higher functional limitations and greater chances of having another stroke $(\mathrm{p}<0.01)$. Patients with simvastatin $40 \mathrm{mg}$ best benefited from the effects of therapy, whereas results from patients treated with simvastatin $20 \mathrm{mg}$ and highintensity statins did not reach sufficient statistical significance to demonstrate the benefit of statins in the context of secondary prevention. Specifically, considering the comparative improvement of patients' functionality after stroke, patients with simvastatin $40 \mathrm{mg}$ and high-powered statins had the best functional recovery over one year $(\mathrm{p}<0.05)$ (Figure 3). Statins were effective in preventing recurrence of another stroke in cases of large-artery atherosclerosis, small-vessel occlusion, and stroke of undetermined cause (Table 3). Interestingly, in the case of stroke classified as cardioembolic or with other determined causes, there was no advantage in the use of statins.

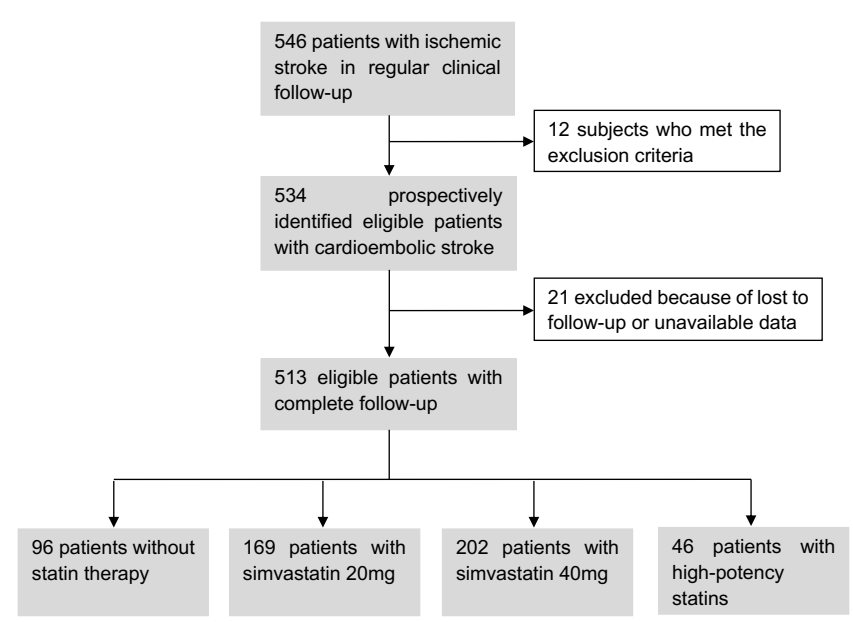

${ }^{*} \mathrm{p}<0.005$.

Figure 1. Flow chart illustrating study design and number of patients. 


\section{DISCUSSION}

In our study, the use of statins was correlated with a reduced risk of stroke recurrence and better functional outcomes. In line with previous studies, being without statins turned out to be at higher risk for a worse prognosis ${ }^{6}$. Although statins were designed to reduce cholesterol levels, the ideal use of these agents and the mechanism by which they protect against cerebrovascular events have been a source of controversy ${ }^{8}$. Recent studies are advocating for a possible role of statins on neuroprotection, improving disabilities ${ }^{13}$. This group of drugs is proven to exert multidirectional effects, interfering with reactive oxygen species development, clot formation, endothelial function, and brain plasticity ${ }^{14}$. Therefore, despite the primary interest and research in statin therapy being about the atherosclerotic pathophysiological mechanism of stroke, there has been emerging evidence of multiple potential beneficial effects of this group of drugs in patients with stroke.

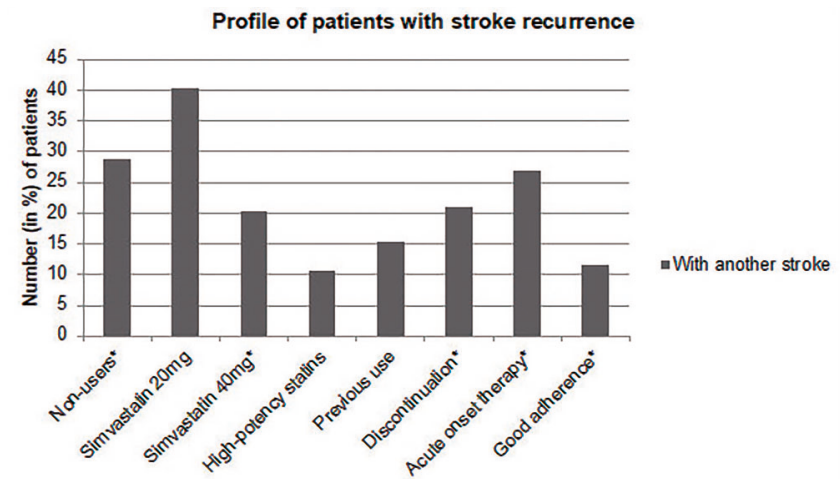

Figure 2. Clinical profile of patients with stroke recurrence.

Table 1. Baseline and clinical characteristics of patients according to statin subgroups.

\begin{tabular}{|c|c|c|c|c|c|c|}
\hline & $\begin{array}{c}\text { Total } \\
\text { (no., \%) }\end{array}$ & $\begin{array}{l}\text { Without statin } \\
\text { (no., \%) }\end{array}$ & $\begin{array}{c}\text { Simvastatin } 20 \mathrm{mg} \\
\text { (no., \%) }\end{array}$ & $\begin{array}{c}\text { Simvastatin } 40 \mathrm{mg} \\
\text { (no., \%) }\end{array}$ & $\begin{array}{l}\text { High-potency } \\
\text { statin }\end{array}$ & $\mathrm{p}$-value \\
\hline Number & $513(100)$ & $96(100)$ & $169(100)$ & $202(100)$ & $46(100)$ & \\
\hline Age, years, mean, SD & $56.7,15.1$ & $48.6,17.2$ & $57.4,15.0$ & $48.6,17.2$ & $62.5,11.8$ & $<0.001$ \\
\hline Female sex & $238(46.4)$ & $51(53.1)$ & $75(44.4)$ & $87(43.1)$ & $25(54.3)$ & 0.33 \\
\hline Hypertension & $357(69.6)$ & $54(56.2)$ & $124(73.4)$ & $141(69.8)$ & $38(82.6)$ & 0.002 \\
\hline Diabetes & $141(27.5)$ & $17(17.7)$ & $46(27.2)$ & $57(28.2)$ & $21(45.6)$ & 0.008 \\
\hline Coronary artery disease & $72(14.0)$ & $3(3.1)$ & $21(12.4)$ & $32(15.8)$ & $16(34.8)$ & $<0.001$ \\
\hline Atrial fibrillation & $61(11.9)$ & $10(10.4)$ & $20(11.8)$ & $23(11.4)$ & $6(13.0)$ & 1.0 \\
\hline Previous stroke & $97(18.9)$ & $15(15.6)$ & $37(21.9)$ & 39 (19.3) & $6(13.0)$ & 0.59 \\
\hline Dyslipidemia & $113(22.0)$ & $9(9.4)$ & $49(29.0)$ & 39 (19.3) & $16(34.8)$ & $<0.001$ \\
\hline Smoking & $177(34.5)$ & $22(22.9)$ & $62(36.7)$ & 75 (37.1) & $18(39.1)$ & 0.08 \\
\hline Alcohol abuse & $68(13.2)$ & $8(8.3)$ & $20(11.8)$ & $36(17.8)$ & $4(8.7)$ & 0.1 \\
\hline Congestive cardiac failure & $46(9.0)$ & $5(5.2)$ & $12(7.1)$ & $23(11.4)$ & $6(13.0)$ & 0.25 \\
\hline Thrombolysis & $45(8.8)$ & $2(2.1)$ & $11(6.5)$ & $29(14.3)$ & $3(6.5)$ & 0.003 \\
\hline Anticoagulation & $106(20.7)$ & $28(29.2)$ & $32(18.9)$ & $37(18.3)$ & $9(19.6)$ & 0.20 \\
\hline Antiplatelets & $391(76.2)$ & $89(92.7)$ & $135(79.9)$ & $163(80.7)$ & $35(76.1)$ & 0.03 \\
\hline Carotid stenosis & $65(12.7)$ & $5(5.2)$ & $21(12.4)$ & $27(13.4)$ & $9(19.6)$ & 0.09 \\
\hline NIHSS, median, (min-max) & $5(0-32)$ & $6(0-23)$ & $5(0-30)$ & $6(0-28)$ & $8(2-28)$ & 0.79 \\
\hline TOAST & & & & & & $<0.001$ \\
\hline Large-artery atherosclerosis & $119(23.2)$ & $12(12.5)$ & $39(23.1)$ & $47(23.3)$ & $21(45.6)$ & \\
\hline Cardioembolism & $103(20.1)$ & $20(20.8)$ & $33(19.5)$ & $42(20.8)$ & $8(17.4)$ & \\
\hline Small-vessel oclusion & $36(7.0)$ & $7(7.1)$ & $13(7.7)$ & $13(6.4)$ & $3(6.5)$ & \\
\hline Stroke of other determined cause & $102(19.9)$ & $38(39.6)$ & $34(20.1)$ & $23(11.4)$ & $7(15.2)$ & \\
\hline Stroke of undetermined cause & $153(29.8)$ & $19(19.8)$ & $50(29.6)$ & $77(38.1)$ & $7(15.2)$ & \\
\hline Discontinuation & $51(9.9)$ & N/A & $25(14.8)$ & $21(10.4)$ & $5(10.9)$ & 0.41 \\
\hline Good adherence of statin & $150(29.2)$ & N/A & $50(29.6)$ & $80(39.6)$ & $20(43.5)$ & 0.07 \\
\hline Early onset of statin & $206(40.1)$ & $\mathrm{N} / \mathrm{A}$ & $75(44.4)$ & $110(54.4)$ & $21(45.6)$ & 0.13 \\
\hline Previous use of statin & $72(14.0)$ & $0(0.0)$ & $25(14.8)$ & $29(14.4)$ & $18(39.1)$ & $<0.001$ \\
\hline
\end{tabular}

*not applicable. 
To our knowledge, we provide the first description of statin prescription from a developing country. Among poststroke statin users, high-intensity use accounted for the smallest part of the patients, which is different from other countries, although the proportion of patients without any statin was similar ${ }^{15}$. Current guidelines do not yet determine the best dose and statin in a stroke setting. In our cohort, high dosages of simvastatin proved to be the most effective treatment modality in improving stroke prognosis. Indeed, the benefit appears to be dose dependent ${ }^{16}$. Interestingly, high-powered statins have not shown significant evidence of interfering with stroke prognosis. One possible reason may come from the fact that they are expensive medications not offered for free in our public health system so that the patient may more quickly, for financial reasons, have poor adherence, delay the onset, or spend a few days without continuous use of the drug. Nevertheless, particularly, simvastatin in the double dose and high-intensity statins showed the most significant ability to recover functional gain in our population, possibly suggesting that such drugs may be preferentially indicated in more severe stroke patients with more significant functional impairment. Our results reflect a worldwide trend that many patients with ischemic stroke may be under-treated ${ }^{15,17}$.
Our study provides a pioneering analysis regarding the comparison of the effect of statins considering the etiology of stroke. Considering the stratification of patients according to TOAST, statins showed positive results for the majority of patients: in cases of large-artery atherosclerosis, small-vessel occlusion, and stroke of undetermined cause. However, our study also suggests that cardioembolic stroke and stroke with other determined cause may not benefit from statin therapy in the same way or at least be less cost-effective. One possible

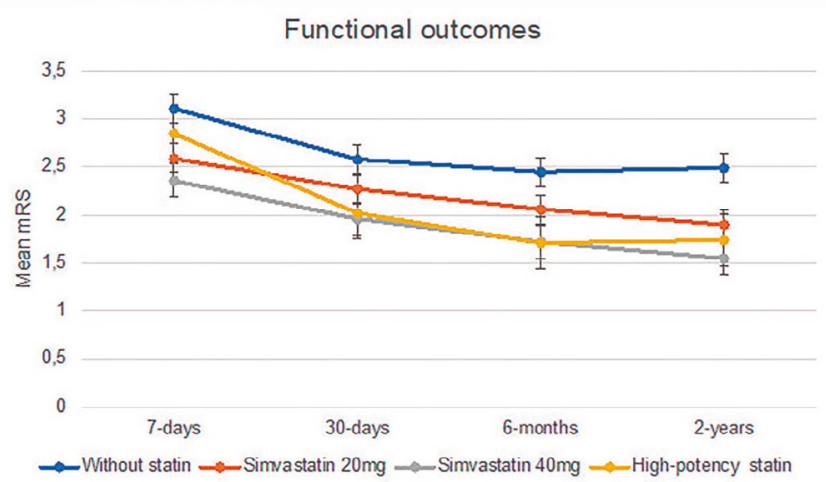

Figure 3. Functional outcome of patients over 2 years after stroke according to statin subgroups.

Table 2. Multivariable analysis of the independent clinical predictors of stroke recurrence and good functional outcome expressed in Odds Ratio with 95\% confidence interval.

\begin{tabular}{|c|c|c|c|c|}
\hline & \multicolumn{2}{|c|}{ Favorable functional outcomes } & \multicolumn{2}{|c|}{ Stroke recurrence } \\
\hline & OR $(95 \% \mathrm{Cl})$ & $p$-value & OR $(95 \% \mathrm{Cl})$ & $\mathrm{p}$-value \\
\hline Without statin & $0.4(0.2-0.7)$ & 0.004 & $2.1(1.3-3.5)$ & 0.005 \\
\hline Simvastatin 20 mg & $0.9(0.6-1.3)$ & 0.61 & $1.5(1.0-2.3)$ & 0.09 \\
\hline Simvastatin 40 mg & $1.7(1.2-2.4)$ & 0.007 & $0.3(0.2-0.5)$ & $<0.001$ \\
\hline High-potency statin & $1.4(0.7-2.7)$ & 0.34 & $1.3(0.6-2.6)$ & 0.65 \\
\hline Previous use & $1.1(0.7-1.9)$ & 0.71 & $1.1(0.6-2.1)$ & 0.77 \\
\hline Discontinuation & $0.4(0.2-0.7)$ & 0.004 & $3.1(1.7-5.7)$ & $<0.001$ \\
\hline Early onset & $1.9(1.3-2.8)$ & $<0.001$ & $0.5(0.3-0.8)$ & 0.003 \\
\hline Good adherence & $4.2(2.7-6.6)$ & $<0.001$ & $0.2(0.1-0.5)$ & $<0.001$ \\
\hline
\end{tabular}

OR: Odds Ratio; 95\%Cl: 95\% confidence interval.

Table 3. Multivariable analysis of the effect of statin use in stroke recurrence and good functional outcome according to TOAST classification. Data are expressed in Odds Ratio with 95\% confidence interval.

\begin{tabular}{lcccc}
\hline \multirow{2}{*}{ TOAST } & \multicolumn{2}{c}{ Favorable functional outcomes } & \multicolumn{2}{c}{ Stroke recurrence } \\
\cline { 2 - 5 } & OR $(95 \% \mathrm{Cl})$ & $\mathrm{p}$-value & OR $(95 \% \mathrm{Cl})$ & $\mathrm{p}$-value \\
\hline Large-artery atherosclerosis & $11.6(1.4-93.3)$ & 0.01 & $0.3(0.08-0.99)$ & 0.09 \\
Cardioembolism & $2.1(0.8-5.5)$ & 0.23 & $0.8(0.3-2.3)$ & 0.88 \\
Small-vessel oclusion & $13.3(11.4-127.6)$ & 0.02 & $0.08(0.01-0.6)$ & 0.02 \\
Stroke of other determined cause & $1.4(0.6-3.2)$ & 0.56 & $0.5(0.1-1.6)$ & 0.35 \\
Stroke of undetermined cause & $2.4(0.9-6.4)$ & 0.11 & $0.3(0.1-0.7)$ & 0.002 \\
\hline
\end{tabular}

OR: Odds Ratio; 95\% Cl: 95\% confidence interval. 
explanation may come from the inherent heterogeneity in these groups of stroke patients. Another pertinent consideration refers to the fact that many of these patients are also anticoagulated, to raise the question of whether statins would add any additional benefit in secondary prevention compared to the use of anticoagulants, for example. In fact, no previous study evaluated the role of statins in poststroke outcomes in these types of patients, since patients enrolled in statins clinical trials were primarily at risk of atherosclerotic carotid or coronary vascular disease ${ }^{18}$. Indeed, current guidelines restrict the recommendation for poststroke statin prescription basically to atherosclerotic stroke patients $^{19}$. Defining whether it is beneficial to prescribe statins for all patients can either save them from the costs and adverse effects of medication or ensure that they take advantage of the effects already evident in patients with other types of stroke ${ }^{20}$. We believe that our results may shed light on this question.

In agreement with previous observations, our study demonstrated that statins are effective in preventing cardiovascular events in stroke victims ${ }^{18,21}$. However, in our study, statins were ineffective in preventing mortality. Possibly, the impact on mortality could be seen in population studies with prolonged follow-up, although a recent meta-analysis corroborated our study indicating that statins do not alter the mortality risk ${ }^{21}$. Hemorrhagic stroke is a controversial possible adverse event that has been associated with statin therapy in some studies ${ }^{22}$. However, in our follow-up, a small prevalence of hemorrhagic stroke was detected that is similar to other observational studies ${ }^{23}$, which cannot be correctly attributed to the use of statins.

Our results regarding are in agreement with previous studies that showed that statin therapy at stroke onset is associated with better outcomes ${ }^{6}$. It seems that time is brain also for statin prescribing. Regarding prior statin use, our results are in line with other studies suggesting the benefit of prior statin use is controversial and may be effective only for restricted patients ${ }^{24,25}$.

Our study has also shown that only proper and continuous use of statins can offer any benefit in stroke patients. We found that patients with poor adherence to treatment present poor prognosis after stroke, which is in line with some previous studies that demonstrated that the suboptimal use of statin in all stroke patients could interrupt the beneficial effects ${ }^{26}$. This is especially important due to the high unsatisfactory adherence rate observed, which is consistent with the rates of a recent study ${ }^{27}$. Besides, we observed that statin therapy discontinuation might imply an increased risk of poor functional outcomes. Indeed, statin withdrawal was already associated with increased risk of early neurological deterioration, dependency after stroke, and all-cause mortality ${ }^{28,29}$. Blanco et al. indicated that statin withdrawal not only suppresses brain protection of previous treatment but causes deleterious effects in comparison with the lack of statinlinked protection at stroke onset ${ }^{28}$.

The strengths of this study include that our study cohort was prospectively followed up, and details could be acquired by a comprehensive review of their medical records, by telephone interviews, and by face-to-face assessments with neurologists. Also, investigators who prescribed statins and those who verified the outcomes were blinded to the study. In our cohort, patients could receive statins regardless of having dyslipidemia. Many previous observational studies that investigated the effects of statins in stroke were biased due to the selection criteria of patients, which compromises the impact of the study ${ }^{20}$. Furthermore, we could perform detailed monitoring of multiple potential confounding factors in our research, and rigorous definitions of outcomes were applied. We also compared different doses and types of statin treatments, which is different from many previous studies that just consider the patient "with or without statin". We are not aware of another study examining statins and multiple long-term outcomes after an ischemic stroke in Brazil.

Some limitations need to be acknowledged to interpret the results better. Because our study is a single-center, hospital-based study, rather than a community-based study, it is unclear to what extent findings can be generalized. Nevertheless, there are no restrictions to be admitted to our hospital, and we included all consecutive cases admitted. Besides, the prospective and single-center design allowed us to collect information systematically and to uniformly verify both the qualifying event as well as follow-up information in all patients, which reduces the risk of information bias. The biases inherent in an observational study are also applicable to our research. It is possible that some variables with an impact on outcomes were not included in our registry, for example. However, conducting a randomized clinical trial would not currently be possible because of the already existing evidence of the benefit of statin therapy for stroke patients. Also, an indication bias may be applicable in our study since the prescription of statins is currently done in an individual and personalized way, since the current guidelines only recommend with precision the use of these drugs in patients with high atherothrombotic risk $^{30}$, which is not necessarily the reality of most patients with stroke.

Overall, this work suggests that statins play an essential role in the treatment of ischemic stroke, preventing stroke recurrence and cardiovascular events, and improving functional performance. Proper adherence to statin therapy, not interrupting treatment, is critical for treatment success. Simvastatin $40 \mathrm{mg}$ seems to be the best option considering the cost-benefit. Additional randomized prospective studies are needed to confirm the effect of statins in the stroke population according to the etiology. 


\section{References}

1. GBD 2015 Neurological Disorders Collaborator Group. Global, regional, and national burden of neurological disorders during 1990-2015: a systematic analysis for the Global Burden of Disease Study 2015. Lancet Neurol. 2017 Nov;16(11):877-97. https//doi. org/10.1016/S1474-4422(17)30299-5

2. Ouriques Martins SC, Sacks C, Hacke W, Brainin M, de Assis Figueiredo F, Marques Pontes-Neto O, et al. Priorities to reduce the burden of stroke in Latin American countries. Lancet Neurol. 2019 Jul;18(7):674-83. https//doi.org/10.1016/S1474-4422(19)30068-7

3. Feigin VL, Norrving B, George MG, Foltz JL, Roth GA, Mensah GA. Prevention of stroke: A strategic global imperative. Nat Rev Neurol. 2016 Sep;12(9):501-12. https//doi.org/10.1038/nrneurol.2016.107

4. Amarenco P, Labreuche J. Lipid management in the prevention of stroke: review and updated meta-analysis of statins for stroke prevention. Lancet Neurol. 2009 May;8(5):453-63. https//doi. org/10.1016/S1474-4422(09)70058-4

5. Squizzato A, Romualdi E, Dentali F, Ageno W. Statins for acute ischemic stroke. Stroke. 2012 Feb;43(2):e18-e19. https//doi. org/10.1161/STROKEAHA.111.638940

6. NíChróinín D, Asplund K, Åsberg S, Callaly E, Cuadrado-Godia E, Díez-Tejedor E, et al. Statin therapy and outcome after ischemic stroke: Systematic review and meta-analysis of observational studies and randomized trials. Stroke. 2013 Feb;44(2):448-56. https//doi.org/10.1161/STROKEAHA.112.668277

7. Katkade VB, Sanders KN, Zou KH. Real world data:An opportunity to supplement existing evidence for the use of long-established medicines in health care decision making. J Multidiscip Healthc. 2018 Jul;11:295-304. https//doi.org/10.2147/JMDH.S160029

8. Castilla-Guerra L, Fernandez-Moreno M del C, Leon-Jimenez D, Rico-Corral MA. Statins in Ischemic stroke prevention: what have we learned in the post-SPARCL (The Stroke Prevention by Aggressive Reduction in Cholesterol Levels) Decade? Curr Treat Options Neurol. 2019 Apr;21(5):22. https//doi.org/10.1007/s11940-019-0563-4

9. Davis SM, Donnan GA. Secondary prevention after ischemic stroke or transient ischemic attack. N Engl J Med. 2012 May;366:1914-22. https//doi.org/10.1056/NEJMcp1107281

10. Smith M, Lee N, Haney E, Carson S, Helfand M. Drug class review HMG-CoA reductase inhibitors (statins) and fixed-dose combination products containing a statin. Portland (OR): Oregon Health \& Science University; 2009

11. Vitturi BK, Pellegrinelli A, Valerio BCO. Medication adherence in patients with myasthenia gravis in Brazil: a cross-sectional study. Acta Neurol Belg. 2020 Feb;120(1):83-9. https//doi.org/10.1007/ s13760-019-01209-0

12. Vitturi BK, Gagliardi RJ. Use of CHADS2 and CHA2DS2-VASc scores to predict prognosis after stroke. Rev Neurol (Paris). 2019 Jun;176(12):85-91. https//doi.org/10.1016/j.neurol.2019.05.001

13. Flint AC, Kamel H, Navi BB, Rao VA, Faigeles BS, Conell C, et al. Statin use during ischemic stroke hospitalization is strongly associated with improved poststroke survival. Stroke. 2012 Jan;43(1):147-54. https//doi.org/10.1161/STROKEAHA.111.627729

14. Amarenco P, Moskowitz MA. The dynamics of statins: From event prevention to neuroprotection. Stroke. 2006 Feb;37(2):294-6. https// doi.org/10.1161/01.STR.0000201856.90105.ab

15. Yang Z, Edwards D, Massou E, Saunders CL, Brayne C, Mant J. Statin use and high-dose statin use after ischemic stroke in the UK: A retrospective cohort study. Clin Epidemiol. 2019 Jun;11:495-508. https//doi.org/10.2147/CLEP.S201983

16. Scheitz JF, Seiffge DJ, Tütüncü S, Gensicke H, Audebert HJ, Bonati LH, et al. Dose-related effects of statins on symptomatic intracerebral hemorrhage and outcome after thrombolysis for ischemic stroke. Stroke. 2014 Feb;45(2):509-14. https//doi. org/10.1161/STROKEAHA.113.002751

17. Canavero I, Cavallini A, Perrone P, Magoni M, Sacchi L, Quaglini S, et al. Clinical factors associated with statins prescription in acute ischemic stroke patients: Findings from the Lombardia Stroke Registry. BMC Neurol. 2014 Mar;14:53. https//doi.org/10.1186/14712377-14-53

18. The Stroke Prevention by Aggressive Reduction in Cholesterol Levels (SPARCL) Investigators. High-dose atorvastatin after stroke or transient ischemic attack. N Engl J Med. 2006 Aug;355(6):549-5. https//doi.org/10.1056/NEJMoa061894

19. Powers WJ, Rabinstein AA, Ackerson T, Adeoye OM, Bambakidis NC, Becker K, et al. 2018 Guidelines for the early management of patients with acute ischemic stroke: a guideline for healthcare professionals from the American Heart Association/ American Stroke Association. Stroke. 2018 Mar;49(3):e46-e110. https//doi.org/10.1161/STR.0000000000000158.

20. Furie KL. High-dose statins should only be used in atherosclerotic strokes. Stroke. 2012 Jul;43(7):1994-5. https//doi.org/10.1161/ STROKEAHA.111.633339

21. Tramacere I, Boncoraglio GB, Banzi R, Del Giovane C, Kwag KH, Squizzato A, et al. Comparison of statins for secondary prevention in patients with ischemic stroke or transient ischemic attack: A systematic review and network meta-analysis. BMC Med. 2019 Mar;17(1):67. https//doi.org/10.1186/s12916-019-1298-5

22. Goldstein LB, Amarenco P, Szarek M, Callahan A 3rd, Hennerici $\mathrm{M}$, Sillesen $\mathrm{H}$, et al. Hemorrhagic stroke in the Stroke Prevention by Aggressive Reduction in Cholesterol Levels study. Neurology. 2008 Jun;70(24 Pt 2):2364-70. https://doi.org/10.1212/01. wnl.0000296277.63350.77

23. Amarenco P, Tonkin AM. Statins for stroke prevention: Disappointment and hope. Circulation. 2004 Jun;109(23 Suppl 1):II44-9. https//doi.org/10.1161/01.cir.0000131518.25959.8f

24. He L, Xu R, Wang J, Zhang L, Zhao W, Dong W. Prestroke statins use reduces oxidized low density lipoprotein levels and improves clinical outcomes in patients with atrial fibrillation related acute ischemic stroke. BMC Neurol. 2019 Oct;19(1):240. https//doi.org/10.1186/ s12883-019-1463-7

25. Reeves MJ, Gargano JW, Luo Z, Mullard AJ, Jacobs BS, Majid A. Effect of pretreatment with statins on ischemic stroke outcomes. Stroke. 2008 Jun;39(6):1779-85. https//doi.org/10.1161/ STROKEAHA.107.501700

26. Kim J, Lee HS, Nam CM, Heo JH. Effects of statin intensity and adherence on the long-term prognosis after acute ischemic stroke. Stroke. 2017 Oct;48(10):2723-30. https//doi.org/10.1161/ STROKEAHA.117.018140

27. Chung PW, Yoon BW, Lee YB, Shin BS, Kim HY, Park JH, et al. Medication Adherence of Statin Users after Acute Ischemic Stroke. Eur Neurol. 2018 Nov;80(1-2):106-14. https//doi. org/10.1159/000493530

28. Blanco M, Nombela F, Castellanos M, Rodriguez-Yáñez M, García-Gil M, Leira R, et al. Statin treatment withdrawal in ischemic stroke: A controlled randomized study. Neurology. 2007 Aug;69(9):904-10. https//doi.org/10.1212/01.wnl.0000269789.09277.47

29. Colivicchi F, Bassi A, Santini M, Caltagirone C. Discontinuation of statin therapy and clinical outcome after ischemic stroke. Stroke. 2007 Oct;38(10):2652-7. https//doi.org/10.1161/ STROKEAHA.107.487017

30. Vitturi BK, Gagliardi RJ. The role of statins in cardioembolic stroke. J Clin Neurosci. 2019 Dec;72:174-9. https//doi.org/10.1016/j. jocn.2019.12.028 